\title{
The khat dilemma in Jimma area: The socio-economic analysis of benefits and harms associated with khat use
}

\author{
Gudina Abashula Fojo *, Abulu Tesfa \\ Jimma University. \\ PO Box 378, Jimma, Oromia, Ethiopia. \\ gudinaabashulafojo@gmail.com \\ * Corresponding Author
}

\section{ARTICLE INFO}

\section{Article History}

Received:

19 August 2019;

Revised:

31 October 2019;

Accepted:

21 January 2020

\section{Keywords}

Khat use;

Dilemma;

Socio-economic

\begin{abstract}
This study aims to come up with empirically based evidence concerning the dilemma of khat (Catha edulis Forsk, a natural green leaf used as a stimulant. This study carried out in selected areas in the Jimma Zone, Oromia National Regional State, South West Ethiopia, in order to clarify the dilemma to use it based on empirical evidence concerning its socio-economic benefits and harms. To this end, 397 samples selected randomly using a probability sampling method from the study areas and a survey undertaken using closed and open-ended questionnaires. Moreover, key informant interviews and focus group discussions carried out in order to collect qualitative data to supplement the survey study. Descriptive statistics like percentages mean and inferential statistics, such as chi-square used to analyze the quantitative data. On the other hand, the thematic analysis used to analyze the qualitative data. The result showed that the respondents had experienced various types of problems they attributed to khat use. As far as the specific economic problems experienced by the respondents were concerned, they were unable to be punctual on work, absent from work, and exposed to unnecessary costs. Moreover, the respondents said that they were unable to save money daily, weekly, or monthly due to expenses attributed to khat chewing. As far as its social harm is concerned, the study participants said that they experienced conflict between themselves and their families due the fact that khat use costs interfered with their families' basic needs expenses. Some of them also mentioned that they conflicted with their bosses because they were not punctual and absent from work due to khat chewing. Similarly, the FGD participants from the community argued that khat chewing has become forcing the jobless segments of the community, mainly to engage in antisocial behaviors such as theft and robbery.
\end{abstract}

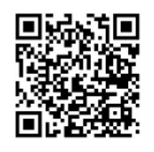

This is an open access article under the $\underline{\mathrm{CC}-\mathrm{BY}-\mathrm{SA}}$ license.

\section{INTRODUCTION}

Khat is a natural green stimulant leaf from the plant scientifically known as Catha edulis, which grows mainly in Ethiopia, Kenya, and Yemen at high altitude areas in South Africa and Madagascar (Weir, 1985). The plant is known by different names in different countries. It is called Chat in Ethiopia, Qat in Yemen, Mirra in Kenya, and Quad or Jaad in Somalia, but in most of the literature, it is known as khat, and this name used throughout this paper (Expert Committee on Drug Dependence of the WHO, 2006). Kath is not common in countries outside of Africa and Arabia. Kath (Cathaedulisforsk) is cultivated and used as a recreational drug predominantly in East Africa and the 
Arabian Peninsula (Toennes \& Kauert, 2002). There is no written evidence concerning when people exactly started to use plants for other purposes than to eat and sustain life. Evidence supplied by both archaeologists and anthropologists, however, suggests that our ancient ancestors used state-altering substances in their everyday life for both sacred and profane reasons for a long time. Evidences are showing that some substances were used for medicinal purposes even in pre-history whilst others use to alter consciousness, religious and recreational ends (Barton, 2011). The same history applies to khat. The exact date when khat started be used world Ethiopia not known due to the dearth of pieces of evidence. However, as lore handed down orally, khat is believed to be originated in Yemen and introduced first to Harar by missionary merchants and gradually expanded to other parts of Ethiopia (Getahun \& Krikorian, 1973).

Currently, khat is grown and consumed in many parts of northeast Africa and the Middle East (Anderson \& Carrier, 2011). It is widely abused in East Africa in general and in Ethiopia in particular for various purposes (Gelaw \& Haile-Amlak, 2004, p. 179). There are more than 10 million people in the world that uses khat daily for its euphonizing and psycho-stimulant effect (Bongard, al'Absi, Khalil, \& Al Habori, 2011). Khat is often used to avoid boredom, to become stimulant and alert. Many people use khat to get temporary to relieve from fatigue, sleep, hunger, and loss of excitation (Megerssa, Esayas, \& Mohamed, 2014). Chewing khat makes one alert and acts as a euphoriant and appetite suppres-sant. In Ethiopia, chewing chat is used by the chewers to stay long hours on laborious activities without feeling boredom. It believed to use for religious contemplation and meditation in both Ethiopia and Yemen. However, the consumption of khat for leisure purposes has been increasing significantly over recent years, and it has been getting indirect institutional recognition in most parts of East Africa and the Red Sea region (Anderson, Beckerleg, Hailu, \& Klein, 2007).

Very few people of specific religious followers, especially the elders, used to chew khat in the past for religious, psychological, social, and healing purposes. However, now it has been widely used among different religious, age, sex, and ethnic groups. Ayana and Mekonen (2004) argue that currently, khat is consumed by almost all segments of the communities in Ethiopia regardless of age, sex, affluence, class, and education, and occupation background. Ashbury (2005) added that khat use in Ethiopia that was limited to very few people in the past has now become expanded to all corner of the country and almost got government recognition indirectly because there is legal ground which forbids its use and it started to serve as a source of national revenue despite the fact that its use is wide-spreading from time to time, there are various controversies over khat use recently. While some groups of people argue that khat has a number of economic and social significance, others counterargue that the social and economic negative consequences of khat out weigh its significance. Hence, there are debates over its positive and negative economic and social gains. Those who argue in favor of khat use argue that the leaf has various economic values as it serves as a source of employment and revenue for a number of its growers and distributors. Apart from the producers and distributors, khat has also become a source of national revenue. For instance, as far as its national economic importance is concerned, in 2010/11 khat was reported to be the third among the top five export commodities in Ethiopia (MOFED, 2011). It is one of the significant sources of foreign exchange earnings to the Ethiopian Economy (Belwal \& Teshome, 2011). It has a significant positive contribution to the Ethiopian economy. It plays a significant role as a source of income for millions of producers, small and large scale traders who directly or indirectly depend on it (Megerssa, Esayas, \& Mohamed, 2014).

Besides, the supporters for khat use also argue that khat stimulates the users, helps them to concentrate, forget fatigues, feel pleasure and stay on high labor demanding activities for a long period without feeling exhaustion. Thus, there is a high demand for the product in the receiving countries too. For instance, the recent daily demand of khat for Djibouti is more than 20 tones and for Somalia, about 50 tones (Belwal \& Teshome, 2011, p. 3641). Moreover, khat brings people together, share ideas on a number of issues with each other and implements the ideas into actual problem solving in their lives which indicates that khat serve as an instrument to facilitate social interactions and knowledge sharing among people (Bongard, al'Absi, Khalil, \& Al Habori, 2011; Gelwa \& HaileAmlak, 2004, p. 182). Thus, khat has now acquired cash crop status in Ethiopia, both at the national and community level. 
Contrary to the advocators of khat use, opponents counter they argue against khat use by enumerating a number of health, social and economic. For instance, khat use has various perceived adverse health effects such as sleeping disorders, reduced appetite, depression, and gastrointestinal (Yahya, Rajeshwar, Eticha, Kahsay, Ali, Gebretsadik, ..., \& Janapati, 2016; Awale \& Ali, 2018). Similarly, khat chewing results in carelessness, frequent absenteeism from work, conflict in the family, the poor academic performance of chewer students, poor confidence, ill-health, poor interaction among the chewer and the rest of the community (Etana, 2018). Hunter, Baker, Gladbaum, Hirani, Mashari, \& McLennan (2012) states that khat believes in contributing to family breakdown and violent behavior. It affects employment prospects a given country as users spend too much time on chewing khat. Moreover, it encourages men to spend too much of their income on the drug rather than on food and other basic necessities of life for their families. It is also argued that there is an association between chronic khat use and the development of psychological symptoms. The psychoactive action of khat hampers the socio-economic and health status of the society. As in most cases, alcohol is used after chewing khat, this also adversely affects the socio-economic and health status of chewers. (Megerssa, Esayas, \& Mohamed, 2014, p. 21). Youngsters spend a session of 3 hours for khat chewing per day, and this undesirably affects labor productivity. Concerning this, Gelaw and Haile-Amlak (2004) indicated that of the 400 respondents they studied, 50.4\% of them were absent from their regular work one or more times in a week to chew khat while $54.5 \%$ of the chewers used to come work late due to chewing khat or leave their work early to chew khat. Yahya et al. (2016) confirmed similar results.

Even though the opponents of khat argue against its use because of its various social and economic consequences, those who support its use counter-argue that there are no proven pieces of evidence between khat use and these negative consequences. For instance, Anderson and Carrier (2011) argue there is no evidence to show a causal relationship between khat use and the various harms khat supposed to be responsible. Sykes, Coleman, Desai, Groom, Gure, and Howart (2010) also argue that users, non-users consider khat use, and many practitioners to be a standard, socially accepted practice, cutting across the social spectrum. Various available arguments khat have been still going on and have been creating confusion for many people as khat is considered as an ordinary vegetable in some countries and a controlled drug in others (Jelsma, Metaal, \& Klein, 2012). Further evidence-based knowledge is still needed to resolve the existing controversies over the use of khat. Whether all users exposed to the said, various harms or not themselves need further empirical-based evidence (Anderson \& Carrier, 2011). Moreover, it was evident that such controversies also put policymakers, practitioners and legal enforcers in dilemmatic situation to take measures either to stop khat use or to allow it. It is essential to examine empirically-based evidence concerning the socioeconomic implications of khat use in order to clarify the dilemma. To this end, it is also essential to investigate the views of khat users, producers, the community and experts on the issue. Therefore, this study conduct to clarify the dilemma associated with khat use. In tandem with this, the study tries explicitly to answer the following research question. That is "what do the socio-economic benefits and harms of khat use imply for the clarification of the dilemma and take decision either to allow or disallow its use publically?".

\section{METHOD}

Both quantitative and qualitative methods of data collection used of the quantitative methods, a household-based survey conducted in the kebeles in the kebeles selected from the woredas and the town. Concerning qualitative methods, focus group discussions (FGDs), in-depth, and key informant interviews carried out to collect data required for the study. A total of ten focus group discussions (1 with producers and 1 with women) in each study area were conducted for this purpose. Ten (10) persons participated in each of the focus group discussions. The FGD participants selected community based on the depth of their knowledge about the socio-economic benefits and harms of khat. Moreover, key informant interviews conducted with one (1) expert in Trade and Industry Office, another one (1) with experts from the Zonal Labor and Social Affairs Office in the respective study sites and three medical doctors (1 from Jimma University specialized hospital and two from Shanan Gibe hospital). 
Study conduct in five woredas consist; Gomma, Manna, Kersa, Dedo, Ommo Nada, and Jimma town. These study sites were purposively selected based on prior information obtained from Jimma Zone Trade and Industry Office. As it is challenging to cover all kebeles in the study sites, three kebeles were again purposively selected from each of the five study woredas based on prior information obtained from the Labour and Social Affairs Offices in the respective woredas. The study populations for this research were khat users and producers communities in the selected woredas and the town covered by the study areas. A household survey found to be the easiest way to select a sample and get access to khat producers and consumers in order to get relevant information for the study. Accordingly, it found that there were a total of 48,227 households in the selected kebeles of the town and woredas for the study according to information obtained from the respective kebeles and towns covered by the study.

Hence, a household-based survey used as nobody has ever compiled and documented data with regards to these target populations. For this reason, households in the kebeles covered by the study sites used to select Khat users. There were a total of 48,227 households in the selected town and woredas, as mentioned above representative sample size calculated from the total households in the study area. The sample size was determined based on the following Slovian's (1964) sample determination formula. The formula is written as $\mathrm{n}=\mathrm{N} /(1+\mathrm{Ne} 2)$ where $\mathrm{n}=$ number of samples, $\mathrm{N}$ $=$ Total population and $\mathrm{e}=$ Error tolerance. The random sampling technique used to select households to be included in the sample. Therefore, 397 samples taken from the population, as mentioned above. Then, sample sizes for each kebeles were calculated proportion to their household size as depicted in the following table, and random sampling used to include the respondents into the sample. The collected data was analyzed using quantitative and qualitative methods of data analysis. Quantitative data was coded and entered into SPSS version 20 and analyzed using descriptive statistics such as percentages, mean, and standard deviations. Chi-square was also used from inferential statistics to analyze the quantitative data. The qualitative data were transcribed, categorized into themes based on the objectives of the study, and analyzed using thematic analysis and narrations.

\section{FINDINGS AND DISCCUSIONS}

This part of the study deals with the analysis of the data obtained from 397 randomly selected individuals, the key informants, and the focus group discussions to address the research objective. The findings focus on the health, economic, and health benefits and harm associate with khat use. It also tries to clarify the dilemma or confusion on the use of khat based on the shreds of evidence from the study participants. Demography of the respondent's khat chewers were males, while $90(22.7 \%)$ of them were females. The majority of the khat chewer respondents were males. The information from the FGD participants and key informants also revealed that khat chewed among males compared to females. Both the FGD and key informant interview participants have mentioned various overlapping reasons regarding khat is more used among males than females. One of these reasons is that women culturally restricted from participating in many of the socially accepted behaviors and activities, let alone chewing khat, which considered as an exception to females according to the socially accepted norm. Thus, women fear to buy and chew khat publicly while the same activity is tolerated for males. The second reason is that women have less access to money to buy whatever they like to buy, including khat compared to their male counterparts as they are financially dependent on their husbands. Even if few of them sometimes get income, their income is so meager to use for other purposes than fulfilling basic needs for their children. They mainly use their money to buy essential goods and services to fulfill basic needs for their children instead of spending instead of buying khat for themselves. Due to these reasons, most women do not chew khat. Very few older women are allowed to chew khat rarely on special events such as mourning, holidays, and marriage ceremonies.

When it comes to the age of the respondents, 57 (14.4\%) of the respondents (khat chewers) were between 18-24 years, whereas 134 (33.8\%) of them were between 25-34 years, those between $35-44$ years constitute $111(28 \%)$ of the respondents, $63(15.9 \%)$ of them were between $45-54$ years, $25(6.3 \%)$ were between 55-65 years and the rest $7(1.8 \%)$ were 60 years and above. The finding shows that majorities of the respondents were those between 25-34 years, which is followed by those 
between 35-44 years. The qualitative information obtained from FGDs indicated that people between this age group mainly engage in laborious activities as compared to the other groups. For this reason, they use khat in order to stay on the laborious activities for a long time without feeling fatigued. As far as the religious backgrounds of the respondents concerned, $94(23.7 \%)$ of the respondents were Orthodox religious followers, $28(7 \%)$ were protestant, $270(68 \%)$ were Islam, $3(0.8 \%)$ were Catholic, and the rest $2(0.5 \%)$ were wakefata religious followers. As far as the religious backgrounds of the respondents are concerned, 94 (23.7\%) of the respondents were Orthodox religious followers, $28(7 \%)$ were protestant, $270(68 \%)$ were Islam, $3(0.8 \%)$ were Catholic, and the rest $2(0.5 \%)$ were wakefata religious followers. This finding indicates that khat use restricted to a single religious follower; rather, it is chewed among different religious followers; however, it mainly chewed among Islam religious followers as compared to the others. This is due to the fact that the majority of the inhabitants in Jimma districts where this study was undertaken are Islam religion followers and some Muslims consider that khat use has religious significance according to the key informant interview with an expert from Jimma zone Labour and Social Affairs Office. Moreover, the FGD participants repeatedly mentioned that khat chewing is historically chewed for religious purposes. This means some Islam religious followers assume that khat chewing has religious significance as it helps a religious person more concentrate, focus, and communicates with the creator, particularly during prayer. Such belief still exists among some of the religious followers, and this is also another reason for the widespread of khat chewing among Muslims, as the study participants argued.

Concerning their educational background, those who cannot read and write constitute $8(2 \%)$ of the respondents, those who can only read and write $68(17.1 \%), 1-4$ grades $45(11.3 \%), 5-8$ grades $75(18.9 \%), 9-10$ grades $92(23.2 \%), 11-12$ grades $39(9.8 \%)$, diploma $37(9.3 \%)$ and degree 33 $(8.3 \%)$. These findings show that khat chewed irrespective of respondents' level of education. The FGD participants and the key informants also frequently mentioned that among all individuals regardless of their level of education. The participants also added that recently khat had become widely used among even among educators and students as it helps them stay on reading for a long time. Regarding the employment background of the respondents, 238 (59.9\%) of them were selfemployed, 147 (37\%) of them were government employees where is the remaining $12(3.1 \%)$ of them were non-government employees. From this finding, it is understood that the majority of the respondents were self-employed.

\section{Harms and benefits associate with khat chewing}

The overall objective of this study is to investigate the harms and benefits associate with khat chewing. To this end, this study tries to examine the economic, social, and emotional and health experiences of khat chewers thematically. The analysis of the empirically based evidence for this purpose begins by scrutinizing the respondents' experience of problem due to khat use and proceeds to the specific ones. Before going into the detail investigation of the respondents' economic and social experiences associated with khat chewing, first of all, it is important to know whether they have experienced any kind of problems they attribute to khat chewing. Accordingly, 362 (91.2\%) of the respondents responded that they had experienced problems due to khat use, where is $35(8.8 \%)$ of them said that they have not experienced problems attributed to khat chewing. These findings indicate that the majority of the respondents have experienced problems associate with khat use. The survey result depicts that the respondents have experienced social and economic problems because of khat chewing. As far as the economic problems are concerned, the respondents mentioned that khat use exposed them to absenteeism from work, unnecessary cost, and inability to save. Moreover, the respondents revealed that they experienced social problems like the conflict with families, particularly with their wives due their inability to provide adequate income for families' basic needs expenses and conflict with their work bosses due to non-punctuality and absenteeism related to khat chewing.

However, not all khat chewers experience problems related to khat chewing in the same way. Chi-square calculated to check whether the experiences of different problems associate with khat use is the same among the respondents. Accordingly, it found that the p-value (.000) is less than the $\delta$ value (0.05). This indicates that there a significant difference among khat users experiences problems 
associate with khat use. One of the variations in the problems they experience may be related to users' weekly frequency of khat chewing. Hence, the Chi-square test used to check the association between the respondents' weekly frequency of khat use and their experience of problems related to khat use using the following hypothesis. H0: There is no association between the respondents' weekly frequency of khat chewing and the experience of problems associate with it. H1: Not H0.

Table 1. Respondents Experiences of Problems Associated with Khat Chewing

\begin{tabular}{lccc}
\hline Experienced problem due to khat chewing? & Frequency & Percent & Valid Percent \\
\hline Yes & 362 & 91.2 & 91.2 \\
No & 35 & 8.8 & 8.8 \\
Total & 397 & 100.0 & 100.0 \\
\hline
\end{tabular}

Table 2. Tests of Association Among The Respondents' Frequency of Chewing Khat and Experience of Problem Associate with It

\begin{tabular}{|c|c|c|}
\hline & $\begin{array}{llll}\begin{array}{l}\text { Respondent's frequency } \\
\text { chewing }\end{array} & \text { of khat } \\
\end{array}$ & $\begin{array}{l}\text { Respondents' experience of problem due to } \\
\text { khat chewing? }\end{array}$ \\
\hline Chi-Square & $126.025^{\mathrm{a}}$ & $269.343^{b}$ \\
\hline $\mathrm{df}$ & 6 & 1 \\
\hline Asymp. Sig. & .000 & .000 \\
\hline
\end{tabular}

a. 0 cells $(0.0 \%)$ have expected frequencies less than 5 . The minimum expected cell frequency is 56.7 .

b. 0 cells $(0.0 \%)$ have expected frequencies less than 5 . The minimum expected cell frequency is 198.5.

As it is seen from the findings in table 2, the p- value (.000) is less than the $\delta$-value $(0.05)$. Then, we should reject the null hypothesis and accept the alternative hypothesis. That means, there is a significant association between the respondents' weekly frequency of khat chewing and the problems they experienced.

Economic problems experienced by the respondents due to khat chewing

Respondents asked about the types of economic problems they faced due to khat chewing. Accordingly, $158(39.8 \%)$ of them said that unnecessary expenses, $12(3 \%)$ inability to be punctual on work, another $12(3 \%)$ said that absenteeism from work, $32(8.1 \%)$ said exposure to unnecessary cost and inability to be punctual on work, $52(13.1 \%)$ said that they were exposed to unnecessary expenses and absenteeism from work where is $39(9.8 \%)$ of them said that they were exposed to unnecessary cost, inability to be punctual on work and absenteeism due to khat chewing. The remaining $92(23.2 \%)$ did not respond to this question as they never experienced the economic problems they attribute khat chewing. From the above findings, it understood that the majority of the survey respondents responded that khat chewing exposed them to unnecessary expenses. They daily invest much amount of money on khat chewing. The following table 5 shows the amount of money spent by the respondents on khat chewing.

The data recapitulations shows, $1(0.3 \%)$ of the respondents said that their daily expenses on khat chewing is 10 birr, 4 (1\%) 15 birr, 64 (16.1\%) 20 birr, 26 (4.5\%) 25 birr, 141 (35.5\%) 30 birr, 50 (12.6\%) 40 birr, 21 (5.3\%) 35 birr, 2 (0.5\%) 45 birr, 77 (19.4\%) of them 50 birr, $2(0.5 \%) 60$ birr, $4(1 \%) 70$ birr and the rest who expend 100 birr and 200 birr constitute $2(0.5 \%)$ and $1(0.3 \%)$ respectively. Khat use not only exposed the respondents to unnecessary expenses but it also negatively affected the respondents' daily, weekly or monthly saving. As Table 3 indicates, 358 $(90.2 \%)$ of the respondents said that they were unable to save money daily, weekly or monthly due to expenses attributed to khat chewing while only $39(9.8 \%)$ of the respondents said that khat chewing expenses did not affect their saving.

The average hours and years spent on chewing khat by the respondents were 3:08 hours and 4.97 years respectively. Similarly, the average amount of money spent by the respondents on khat chewing is 35.02 Birr. 
Table 3. The Effect of Khat Expense on The Respondents' Saving

\begin{tabular}{lccc}
\hline Save money daily, weekly or monthly? & Frequency & Percent & $\begin{array}{c}\text { Valid } \\
\text { Percent }\end{array}$ \\
\hline Yes & 39 & 9.8 & 9.8 \\
No & 358 & 90.2 & 90.2 \\
Total & 397 & 100.0 & 100.0 \\
Inability to save money attributed to khat use? & & & \\
Yes & 358 & 90.2 & 90.2 \\
No & 39 & 9.8 & 9.8 \\
Total & 397 & 100.0 & 100.0 \\
\hline
\end{tabular}

Table 4. Respondents' Average Hours, Daily Expenses and Years and Spent on Khat Chewing

\begin{tabular}{lccccc}
\hline Variable & N & Minimum & Maximum & Mean & $\begin{array}{c}\text { Std. } \\
\text { Deviation }\end{array}$ \\
\hline Hours daily spent on chewing khat & 397 & 1 & 6 & $3: 08$ & .912 \\
Daily expense on khat in birr & 397 & 10 & 200 & 35.02 & 15.204 \\
Years spent on chewing khat & 397 & 1 & 17 & 4.97 & 2.355 \\
\hline
\end{tabular}

Table 5. Respondents' Weekly Frequency of Khat Use

\begin{tabular}{lccc}
\hline Weekly khat use & Frequency & Percent & Valid Percent \\
\hline One time in a week & 62 & 15.6 & 15.6 \\
Two times in a week & 104 & 26.2 & 26.2 \\
Three times in a week & 60 & 15.1 & 15.1 \\
Four times a week & 40 & 10.1 & 10.1 \\
five times a week & 39 & 9.8 & 9.8 \\
Six times a week & 91 & 22.9 & 22.9 \\
Missing & 1 & .3 & .3 \\
Total & 397 & 100.0 & 100.0 \\
\hline
\end{tabular}

According to Table 5 shows that $62(15.6 \%)$ of the respondents chew (use) khat one time in a week, $104(26.2 \%)$ two times in a week, $60(15.1 \%)$ three times a week, $40(10.1 \%)$ four times a week, $39(9.8 \%)$ five times a week and $91(22.9 \%)$ of them six times a week. Here, it is important to keep in mind that how often the respondents use khat has a relationship with the various type problems they face as a result. The respondents also asked about how much time they spend on khat chewing. As table 5 above depicts, $41(10.3 \%)$ of them responded that they spent 0:30 hours, 96 (24.2\%) 1:00 hours, 234 (58.9\%) 2:00 hours, 11 (2.8\%) 3:00 hours, 7 (1.8\%) 4:00 hours and the rest $8(2 \%) 5$ and above hours. Khat chewing has various economic problems for the users and their families, as understood from the above-discussed survey findings.

Table 6. Respondents' Weekly Time Spent on Khat Chewing

\begin{tabular}{lccc}
\hline Hours spent on chewing & Frequency & Percent & Valid Percent \\
\hline $0: 30$ hours & 41 & 10.3 & 10.3 \\
1:00 hours & 96 & 24.2 & 24.2 \\
2:00 hours & 234 & 58.9 & 58.9 \\
3:00 hours & 11 & 2.8 & 2.8 \\
4:00 hours & 7 & 1.8 & 1.8 \\
5 and above hours & 8 & 2.0 & 2.0 \\
Total & 397 & 100.0 & 100.0 \\
\hline
\end{tabular}


Qualitative pieces of evidence from the open-ended questionnaire responded by khat users revealed that khat chewing mainly associates with non-punctuality and absenteeism from work. The economic problem associate with khat chewing is manifested in many ways, as the study participants revealed. Khat chewers invest a lot of their daily income on khat use, and this compromises their expenses for families' basic needs. In connection with this, women FGD participants complained that most of their husbands were daily laborers, and they earn 30- 50 birrs daily wage labor, and they are mainly the only source of income to their families. This amount of daily income is very small these days for households having many children as the cost of living is increasing from time to time, as described by the participants. However, despite the fact that their income is meager and the cost of living is getting expensive from time to time, the husbands spent much amount of their daily earning on buying khat and things like peanut, sugar, and soft drinking, which are often used during khat chewing sessions. Those chewers who have habits of drinking after khat chewing even spend equal or sometimes more than what they expend for buying khat and its 'accessories.'

Consequently, many husbands give a small amount of money to their wives to buy food, clothes, and buy school materials for children. Even there are times when some of them do not give a coin to the wives for household basic needs expenses. In such extreme cases, women forced to collect and sell firewood or charcoal in addition to their domestic activities to secure daily survival needs for their children as the women FGD participants repeatedly complained. It shows that khat is being chewed by husbands at the expense of the family budget for basic needs. According to the informant, I also agree with the economic problems complaints of the women FGD participants about the interference of the husbands' khat expenses with that of the family expenses for basic needs. In relation to this, the key informant from Labor and Social Affairs Office described that an individual person invests 30-70 birr daily on buying khat. This is not an easy expense because this means the person expends about 900-2100 birr on khat use monthly, which is equivalent to a monthly salary of diploma holders in Ethiopia. Khat chewing related economic problem has been creating hardships for many people, especially breadwinners, to cover their families' essential needs. In relation to khat expenses, there are times when husbands lack money for families' basic needs and get into conflict with their wives consequently.

Almost all the individual study participants whom their economic problem experiences related to khat chewing quoted above, the key informants and the FGD participants have a similar idea on the economic problems associated with khat chewing. They all share the same idea concerning the financial loss associate with khat chewing except those who participated in the producers FGD and the key informant from Trade and Industry office. The producers FGD participants argued that khat alone should not blame for causing financial loss to the chewers because the purpose for which people chew khat and manage expense also matters. According to these FGD participants, if people chew khat for undertaking financially gainful activities, this should not be considered as if they are wasting money because they are getting energy from khat to work for a long time and to generate income. In other words, this means they are replacing the cost they incur on buying khat from the income they get from the activities they are undertaking. In such circumstances, khat chewing is not economically disadvantaged. Moreover, khat is a source of employment and income for several khat producers and traders. A single producer gets roughly 10,000 birr- 15,000 birrs from a $100 \mathrm{sqm}$ plot of khat land annually. This is not an easy income. It is by far more than the income obtained from the same plot of coffee land. Khat is also a source of revenue for the government, too, according to the FGD participants from the producers. Therefore, khat is useful for the producers, the distributors, and the government, and the nation at all. According to the producers, participated in the FGD is also useful for the consumers, too, if they use it wisely.

The key informant interviewed from Trade and Industry Office shares a similar idea with the producers regarding the economic benefits of khat. According to this informant, khat has become one of the cash crops in Ethiopia. Like coffee and other and other cash crops, many tones of khat supplied to the domestic market and foreign market much money collected from khat trade and tax. Overall, revenue estimated in millions of birr is collected annually from khat to support other sources of the annual government budget to provide different social services and expand public infrastructures. This key informant stressed that khat has many contributions to the economy of the country. 
He also added that there is no scientific evidence-based khat use related harm recorded yet, and there is no evidence to say that khat is harmful. Khat use may become economically burden to the consumers if they use it without purpose. Like with the consumers' FGD participants, this key informant emphasized that if people use it while undertaking economically useful activities, the income they get from the activities will counterbalance their expenditure.

On the contrary, the women FGD participants and the other key informants argued that the said economic benefits of khat for the producers is obtained at the expense of tremendous social and economic costs for the majority of the community. According to the key informant interviewee from Labour and Social Affairs, one of the economic costs of khat is that producers have been expanding khat cultivation by turning the agricultural land should have to be used for cereal crops, coffee, and other important vegetables to khat land. This has a clear negative impact on the amount of food produced for the community. Recently, the community has been affected by food shortage from time to time because the same attention given for other cash crops especially for khat by farmers is not being given for cereal crops according to the key informant because the income the farmers get from small plot of khat land has become by far greater than the income they obtain from other cereals or cash crops from the same plot of land. One of the medical doctors also argued that such differential attention given for khat production, in the long run, affects the production of different types of crops, which in turn affects communities' access to a balanced diet.

Both the women's and the producers' FGD participants themselves share the same idea with the key informant regarding this. The women FGD participants argued that their husbands do not give the same attention they give for khat production to other cereal crops. The producers themselves have witnessed that they have been giving much attention to khat production as they believe that more income obtained from khat compared to selling the same amount of crop. The justification is that they get better income from khat as compared to cereal crops. Hence, it is possible to buy the cereal crops used for food from other areas for consumption, even if it is not possible to produce the required amount. The other economic harm of khat use, as argued by the study participant, is the harm related to the time khat users invest in khat use. According to the women FGD participants, very few people use khat for productive activities. Most khat users simply sit down and use khat frequently for a long time without engaging in any activity. If the time lost on khat chewing used for other economic activities, it will contribute much to the prosperity of the individual khat users, their families, and even to the country.

Similar to the women FGD participants, the key informant interviewed from Labor and Social Affairs Office emphasized that khat is used particularly among the youths, and the majority of the youths are unemployed, which means they chew khat mainly as they are idle. In otherworld, they invest much time on khat without engaging in income-generating activities or having an income that replaces their expense. Even those people who have regular sources of income simply sit down and chew khat most of the time. They often start work after they got stimulated or become high and too much time on khat chewing. Though the intention of chewing khat is to be stimulated and stay on work for a long time without feeling fatigued, in reality, the stimulation helps the user to get concentrated and stay on the activity for a shorter period of time in most cases than the time spent on chewing the khat according to this key informant. Thus, the argument about khat is used for economically gainful activity is less convincing as this key informant described. In the same manner, all the key informants and FGD participants revealed that there is a high possibility for khat chewers to become exposed to a host of addictive behaviors such as alcohol drinking, smoking cigarettes, and even other drugs. The participants have also added that there is the widespread use of drugs like hashish and ganja among khat chewers. These behaviors are not only economically disadvantages to the person become addicted to these behaviors, but also it is a threat to the community because most of the khat and other drug users get the money they need for this addictive behavior through illegal means such as theft and robbery. A number of theft and robbery cases have been reporting from the community to the police for the past few years. These are a clear indication of the widespread use of khat and its associated addictive behaviors, particularly among the unemployed youths, according to the FGD and key informant participants. 
Social Benefits and Harms of Khat

Table 7. Types of Social Problems Experienced by the Respondents

\begin{tabular}{llll}
\hline \multicolumn{1}{c}{ Types of social problem } & Frequency & Percent & $\begin{array}{l}\text { Valid } \\
\text { Percent }\end{array}$ \\
\hline Conflict with family member/s & 77 & 19.4 & 19.4 \\
Conflict with friends & 8 & 2.0 & 2.0 \\
Failure to shoulder family roles and responsibilities & 34 & 8.6 & 8.6 \\
Conflict with family members and friends & 9 & 2.3 & 2.3 \\
Conflict with family members and failure to shoulder responsibility & 72 & 18.1 & 18.1 \\
Missing & 175 & 44.1 & 44.1 \\
Conflict with family members, friends and failure to shoulder & 22 & 5.5 & 5.5 \\
responsibility & 397 & 100.0 & 100.0 \\
Total & & & \\
\hline
\end{tabular}

The study also tried to investigate the social harms and benefits of khat chewing based on the chewers' experiences. As far as the social harms are concerned, the respondents asked about the types of social problems they experienced as a consequence of khat chewing. As Table 7 shows 77 $(19.4 \%)$ of them said that they experienced conflict with family members, $8(2 \%)$ of them said conflict with friends, $34(8.6 \%)$ of them said that failure to shoulder family roles and responsibilities, $9(2.3 \%)$ conflict with family members and friends, $72(18.1 \%)$ conflict with family members and failure to shoulder responsibility, $22(5.5 \%)$ conflict with family members, friends and failure to shoulder responsibility were $75(44.1 \%)$ of them missed this question because they never experienced social problem/s they attribute khat chewing. Further detail investigation made to identify in what ways the different types of social problems respondents experienced are related to khat chewing. Accordingly, the following statements were forwarded by the survey respondents to the open-ended question included in the study for this purpose.

"I expend much money on khat chewing. This intervenes with the expenses for my family's basic needs and children's educational materials. Hence, I frequently conflicted with my wife as a consequence" (33 years old study participant). "Whenever I chew khat, I frequently absent from work. Thus, I conflicted with my boss, and a warning letter was written against me (39 years old male study participant)". "I often experienced a shortage of money to buy khat and borrowed from my friends. Nevertheless, I fail to return it on time, and hence we exchanged offensive words each other (31 years old, male study participant)".

In the same manner, the non-khat producers FGD participants, and key informants argued that khat has numerous social problems. It has become mainly chewed by the unemployed, especially the youths. This segment of the community sits down and chews khat daily. Khat has hampered the creativity and motivation of youths to work. Many youths have become expecting their families for everything, including their basic needs instead of working and improving themselves economically. This is a great social and economic loss to the community because, on the one hand, khat is creating dependency; on the other hand, the fact this social segment of the community has become idle means it is a loss of active human labor which plays a decisive role in the economic and social development of a given community.

Furthermore, khat chewers, in general, and the youths, in particular, have separated themselves from the rest of the community and created their own isolated world where they develop anti-social deviant behaviors. In this regard, khat has, for instance, become the primary source of different types of social ills such as robbing and theft that have become wide-spreading from time to time and mainly committed by youths, according to the study participants. Contrary to its social harms, few study participants described that khat has some social benefits. Khat mainly chewed in the group. Khat chewing brings people together. Whenever people come together for khat chewing, they exchange information on personal and public issues which worry them and search solution for it. 
Khat chewing help chewers to keep in touch with various events that take place in their community as it helps them come together and exchange information. In their responses to the openended question to elicit the social advantages of khat, the respondents have described their experiences as follows.

We chew khat mainly in a group. When we come together for chewing, we do not only sit together to chew khat alone. Instead, we discuss many matters that affect our lives. Khat chewing facilitates discussion forum among people. For example, we discuss how to get income, improve our health, and support each other in times of difficulties. (43 years old, male survey respondent).

The other study participant illustrated that khat makes the chewer very passive, and hence the possibility the chewer becomes in conflict with other people over various issues decreases. Instead, whenever people come together for chewing, they form agreement and friendship. This study participant has elaborated on this argument as follows.

Whenever I chew khat, I do not care about other people. When I become stimulated, I forget worrying about everything, feel pleasure, get concentration on whatever I do, or chat with friends. It creates a lovely world in which I enjoy a peaceful relationship. (33 Years old male study participant).

It can conclude that the use of Khat in some communities also has adverse risks and impacts. As in Kebede, Alem, Mitike, Enquselassie, Berhane, Abebe, ... \& Gebremichael (2005) study, most teenage dropouts are involved in risky sex. The use of Khat and alcohol and other substances is significantly and independently associated with risky sexual behavior among Ethiopian youth. It can also be seen from the use of Khat leaves related to its effect when compared to the prevalence of smoking; it seems to decrease among students. However, the decrease in the prevalence of chewing khat is not extraordinary (Kebede, 2002). Students know the most common health risks associated with smoking. Teachers in high schools and colleges, parents, mass media, and other concerned people must teach students about health and social issues related to smoking and chewing cigarettes.

\section{CONCLUSION}

This study intended to examine the socio-economic and health harms and benefits associate with khat chewing. Accordingly, 397 khat chewers were randomly selected, and the survey conducted. Moreover, FGDs and key informant interviews were undertaken to collect qualitative information. It supplements the quantitative information from the survey study. The findings of the study indicated that Khat chewing has profound socio-economic and health consequences on the chewers. To mention a few of its negative economic consequences, khat chewers exposed to unnecessary expenses to the extent that it compromised the fulfillment of the basic needs of their families. Due to expenses of khat and the associated substances consumed during and after khat chewing, respondents revealed that their ability to save a particular part of their daily income for difficult times is severely affected. As khat chewing requires them a long time, and it followed with exhaustiveness, respondents also frequently failed to be punctual and absent from work. This made the conflict with their bosses. Apart from these, khat chewing associated with smoking cigarettes and alcohol drinking, which exacerbates the economy of its users due to high expenses and low saving resulted from khat chewing. As khat production has been expanding at the expense of other crops cultivation, this will have its own negative effects on the future production and productivity of the community. Finally, the search for money to buy khat and its associate addiction behaviors such as smoking cigarettes and drinking alcohol have been influencing some of the users to engage in antisocial behaviors such as theft and robbing.

Even though khat has numerous economic and social harms, it will continue to be produced and consumed among the community because there is no consensus among the consumers, the producers, the experts, the government, and the community at large concerning the harms associate with khat chewing. The consumers, experts, and the community argue that khat has several economic and social harms. In contrast, the producers and the government body argues that khat is one of the 
major cash crops, which is the source of revenue for many producers, distributors, and the nation. The producers and concerned government bodies further argue that there are no empirical evidencebased harms of khat. Thus, attempts made to reduce khat use will remain to be controversial and dilemmatic until the concerned actors reach consensus about the negative consequences and take actions to reduce its harms.

\section{REFERENCES}

Anderson, D. M., \& Carrier, N. C. M. (2011). Khat: Social harms and legislation, a literature review. Home Office.

Anderson, D. M., Beckerleg, S., Hailu, D. and Klein, A. (2007). The Khat Controversy: Stimulating the drugs debate. Berg

Ashbury, H. (2009). Free Medical Clinic. Haight-Ashbury Publications.

Awale, S. S. A., \& Ali, A. Y. S. (2018). Social and economic difficulties caused by khat usage in Somalia. International Journal of Humanities and social Science, 8(8), 184-198. Doi: https://doi.org/10.30845/ijhss.v8n8p21

Ayana \& Mekonen (2004). Khat (Catha edulis Forsk) chewing, socio-demographic description and its effect on academic performance, Jimma University.

Barton, A. (2011). Illicit Drugs Use and Control. United Kingdom: Routledge.

Belwal, R., \& Teshome, H. (2011). Khat exports and the Ethiopian economy: Opportunities, dilemmas and constraints. African Journal of Business Management, 5(9), 3635-3648. Doi: https://doi.org/10.5897/AJBM09.342

Bongard, S., al'Absi, M., Khalil, N. S., \& Al Habori, M. (2011). Khat use and trait anger: Effects on affect regulation during an acute stressful challenge. European Addiction Research, 17(6), 285-291. Doi: https://doi.org/10.1159/000330317

Etana, M. B. (2018). Economic and Social Impacts of Khat(Catha edulis Forsk) among Youths in Sebeta Town, Oromia, Ethiopia. Biomedical Statistics and Informatics, 3(2), 29-33. Doi: https://doi.org/10.11648/j.bsi.20180302.14

Hunter, A., Baker, E., Gladbaum, H., Hirani, K., Mashari, R., \& McLennan, M. (2012). The health and social impacts of khat use in Brent. Brent: Brent Council.

Gelaw, Y., \& Haile-Amlak, A. (2004). Khat chewing and its socio-demographic correlates among the staff of Jimma University. Ethiopian Journal of Health Development, 18(3), 179-184.

Getahun, A., \& Krikorian, A. D. (1973). Chat: Coffee's rival from Harar, Ethiopia. Botany, cultivation and use. Econ Bot (Economic Botany), 27(4), 353-377. doi: https://doi.org/10.1007/BF02860690

Jelsma, M., Metaal, P., \& Axel, K. (2012). Chewing over Khat prohibition: The globalization of control and regulation of an ancient stimulant. Transnational Institute. Amsterdam.

Kebede, D., Alem, A., Mitike, G., Enquselassie, F., Berhane, F., Abebe, Y., Ayele, R., Lemma, W., Assefa, T., \& Gebremichael, T. (2005). Khat and alcohol use and risky sex behaviour among in-school and out-of-school youth in Ethiopia. BMC public health, 5(1). Doi: https://doi.org/10.1186/1471-2458-5-109

Kebede, Y. (2002). Cigarette smoking and khat chewing among college students in North West Ethiopia. Ethiopian Journal of Health Development, 16(1), 9-17. Doi: https://doi.org/10.4314/ejhd.v16i1.9818

Megerssa, B., Esayas, A., \& Mohamed, A. (2014). Socio-Economic Impact of khat in Mana District, Jimma zone, South Western Ethiopia. Discourse Journal of Agriculture and Food Sciences, $2(2), 21-32$. 
Ministry of Finance and Economic Development (MoFED). (2005). Survey of the Ethiopian Economy II Review of Development during 1998/99-2003/04: A Publication of the Development Planning and Research Department.

Sykes, W., Coleman, N., Desai, P., Groom, C., Gure, M., \& Howart, R.(2010). Perceptions of the social harms associated with khat use. London: Home Office.

Toennes, S. W., \& Kauert, G. P. (2002). Excreation and detection of cathinone, cathine, and phenylpropanolaminein urine after kath chewing. Clinical Chemistry, 48(10), 1715-1719. doi: https://doi.org/10.1093/clinchem/48.10.1715

Weir, S. (1985). Qat in Yemen: Consumption and social changes. Sana'a.

Yahya, A., Rajeshwar, Y., Eticha, T., Kahsay, G., Ali, D., Gebretsadik, H., Gebretsadik, T., \& Janapati, Y. K. (2016). Socio-economic and health effects of khat chewing in Mekele, Tigray Region, Ethiopia. International Journal of Pharmacy and Pharmaceutical Research, 8(1), $1-22$. 